\title{
Molecular Gastronomy: Materials Science in the Kitchen
}

Colin McCormick and Sharka Prokes

To many scientists, food is only about nutrition. These scientists think of food as something to eat quickly, without much attention, in order to get back to doing science without being hungry. But for others, food is science. For the past two decades, a small group of scientifically minded chefs in kitchens around the world has been using techniques borrowed from materials science to create beautiful, fascinating, and unique dishes, delighting diners from Barcelona to Paris to New York. These chefs are at the forefront of a growing movement known as "molecular gastronomy," which has been described as "the chemistry and physics behind the preparation of any dish: for example, why a mayonnaise becomes firm or why a soufflé swells."**

We were intrigued by this example of materials science being used outside of a laboratory, and we decided to sample it at Washington DC's minibar, the brainchild (and playground) of celebrity chef José Andrés. True to its name, minibar is a tiny restaurant-within-a-restaurant, made up of a small row of six seats nestled to one side of the main dining room of Andrés's more mainstream seafood restaurant. Andrés and his small minibar staff serve a remarkable meal of two dozen tiny, beautiful dishes to dazzled patrons most nights of the year. The food is very laborintensive: four sous-chefs work from 8:00 a.m. to 6:00 p.m. to prepare the ingredients, which are assembled and served right in front of the customers. And each dish is the result of a research and development process that can take months of work in Andrés's kitchen laboratory.

Arriving at the restaurant on a Tuesday evening, we were given a small "hot and cold" pisco sour cocktail to begin the meal. The materials science nature of the food was immediately evident from this drink, since it was made from a liquidnitrogen-cooled liquid topped with a layer of egg white fluffed up with nitrous oxide. Once we finished our drink, the chefs served us an "Olive Oil Bon-Bon," a small drop of olive oil encased in crystallized isomalt, a sugar substitute made from beet extract. Isomalt has the useful property of having a high caramelization temperature, meaning that it can be easily crystallized without browning, which would have spoiled the beautiful goldengreen appearance of the treat. Popping it into our mouths, we crunched through the sweet exterior, releasing a spurt of

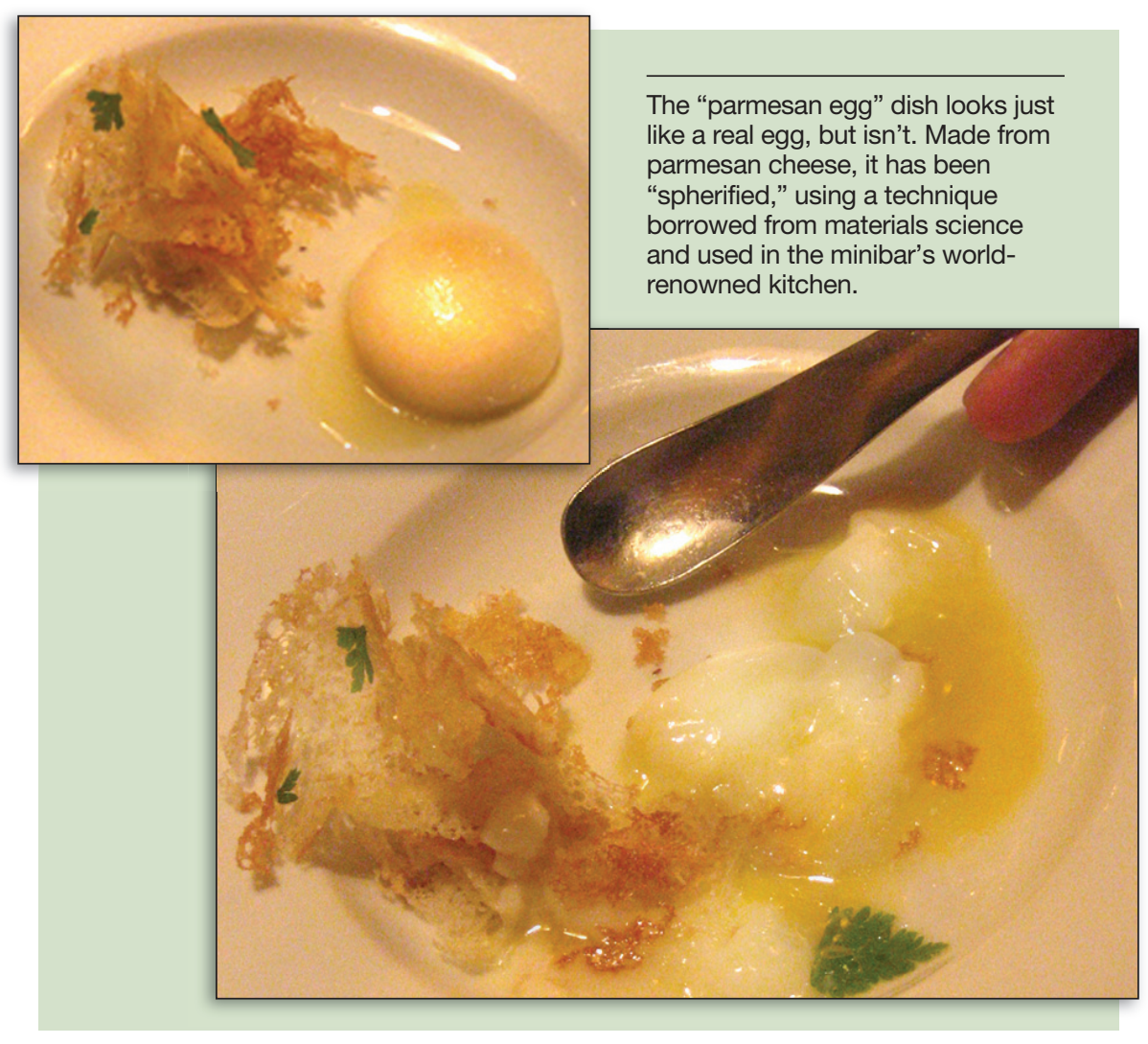

olive oil that mixed nicely with the isomalt's flavor. (Isomalt also has a relatively small negative heat of solution, so it displays very little "cooling effect" when it is placed on the tongue. Xylitol, a related polyol sugar substitute, has a much larger cooling effect, and it is often used in candy that seeks to achieve a "minty fresh" effect in the mouth.)

Shortly after the olive oil bon-bon, we were served a dish called "Dragon's Breath Popcorn," which won our vote for the most creative dish of the evening. It consisted of small cubes of crushed popcorn kernels held together with caramel. Before serving the cubes, the chefs dipped them into liquid nitrogen, and then instructed us to immediately put them in our mouths. As is obvious to anyone who has handled liquid nitrogen, this seemed like a very bad idea. But the chefs assured us it was safe, so we followed their instructions and found the cubes remarkably tasty, and only slightly cool to the

INTERFACES seeks articles featuring the people and profession of materials. Send proposals to Bulletin@mrs.org. tongue. Surprised, we turned to each other and exhaled through our nosesmaking two billowing streams of smoke! After we had finished laughing, the chefs explained to us that this popcorn was extremely dry, meaning that its flavor did not change significantly at low temperature. But more importantly, the lack of water meant that the mixture had a low specific heat capacity, making it safe to put a few cubic centimeters of it into our mouths at liquid nitrogen temperatures. (This is the opposite of what happens when you eat a hot slice of Hawaiian pizza: the water-rich pineapple chunks, which have a high heat capacity, burn your mouth by releasing lots of energy as they equilibrate with your body temperature.) Even though it did not cold-burn our mouths, the popcorn cooled down the air inside our throats, causing water vapor to condense in the air we exhaled, making the "dragon's breath."

One of the most notable molecular gastronomy techniques is spherification, in which chefs make spheres of liquefied foods with an outer "skin" containing the inner liquid. We had a chance to sample this technique with the "Parmesan 'Egg' with Migas" dish served mid-way through the meal. We were served what 
appeared to be a regular egg yolk, and when we cut into it with our spoons, a runny center flowed out just like a normal egg. However, the chefs explained that these eggs had never seen the inside of a chicken-instead, they were parmesancheese-based concoctions that had been spherified. This trick, developed in 2003 by Jose Andrés's mentor Ferran Adrià, is based on a reaction between calcium chloride and sodium alginate. By adding a small amount of sodium alginate to a liquid (Adrià famously uses olive oil) and releasing drops of it into a water solution containing calcium chloride, calcium ions displace sodium ions and cross-link the alginate, forming a gel. Since this initially occurs on the outer surface of the liquid food drops, the gel acts as a skin. In Adrià's early experiments with the technique (inspired by observing the industrial application of alginates) the resulting spheres had to be eaten quickly, since the calcium ions continued to diffuse inward, gelling the entire sphere. He soon learned to invert the process, adding calcium chloride to the food liquid and dropping it into a water solution of sodium alginate. In addition to the reconstructed egg and olive spheres, Adrià and others have delighted eaters with such spherified creations as liquid pea ravioli, liquid mango ravioli, and "reconstructed" tomatoes.

Another signature molecular gastronomy technique is the use of foams. If you look at the food in your pantry and refrigerator, you will find that there are very few pure compounds and true homogeneous solutions (sugar, salt, sodium bicarbonate, some soft drinks, and some refined vegetable oils are the main exceptions). Almost everything else is in the form of dispersions, that is, more or less stable combinations of compounds or phases that do not mix. Depending on the state of the immiscible compounds, dispersions can be colloids, aerosols, emulsions, or foams. Molecular gastronomy chefs make great use of powdered soy lecithin, which allows them to create foams out of fat and water, which do not normally blend together. This leads to flavorful concoctions that do not clutter plates with large amounts of water or change the texture of foods, but impart bursts of flavor. Several of the minibar dishes included foams made from lemon zest, giving a tangy citrus taste to foods ranging from a brioche to oysters to lobster. Other chefs use foams based on almost every conceivable food, including beet juice, chocolate, hot dogs, or wasabi.

When talking about molecular gastronomy, some people are quick to point out that scientists have worked on food, particularly food safety, for decades. But

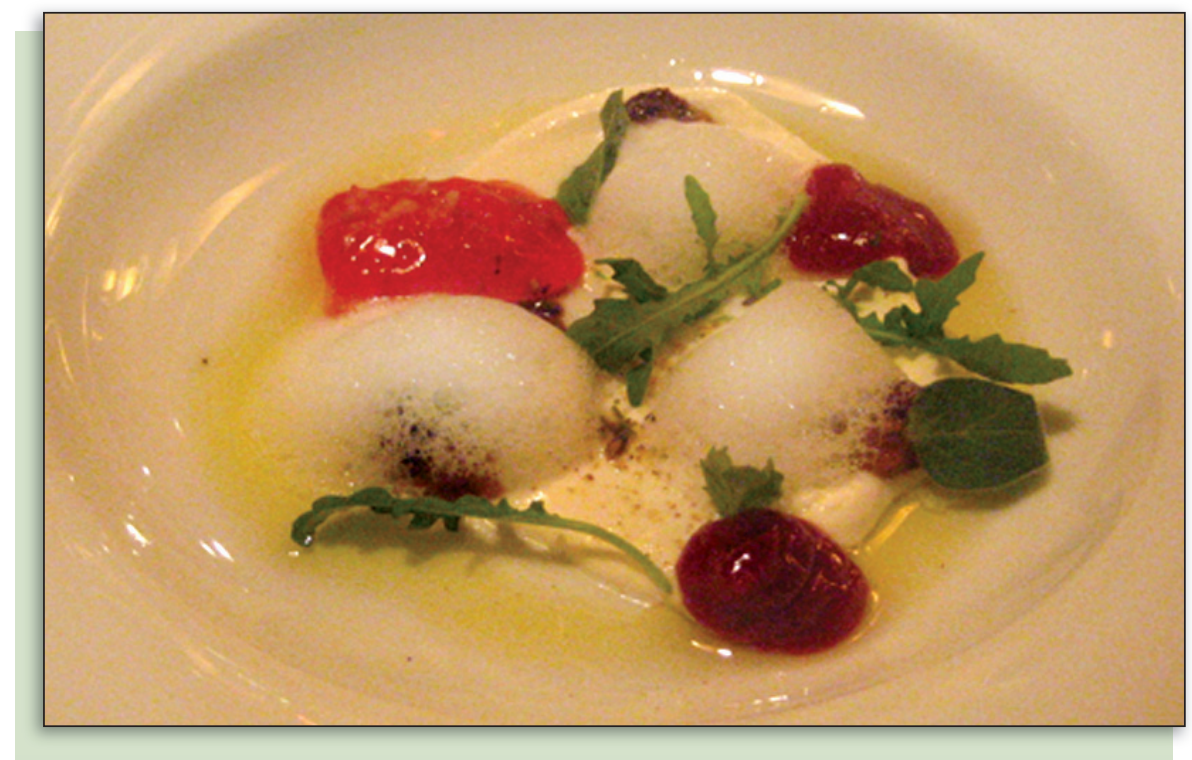

The "sun-dried tomato salad" dish is topped with a foam made from lemon zest.

molecular gastronomy distinguishes itself by focusing on the small-scale preparation of individual food items and meals, with an emphasis on using science to debunk myths about food preparation and create more interesting and delicious experiences for eaters. The movement traces its roots to 1992, when the first International Workshop on Molecular and Physical Gastronomy was held at the Ettore Majorana Center for Scientific Culture in Sicily, co-directed by Oxford physicist Nicholas Kurti, French physical chemist Hervé This, and U.S. science writer Harold McGee. California chef Elizabeth Cawdry Thomas and Professor Ugo Valdrè of the University of Bologna were also involved in the genesis of these meetings, which have continued every few years with themes like "Heat in Cooking" and "The Interaction of Food and Liquids." Today, chefs in many restaurants serve dishes inspired by these early pioneers and others who love both food and experimentation.

Unfortunately, we did not get a chance to sample one of the other notable molecular gastronomy techniques, the use of transglutaminase, or "meat glue." An enzyme derived from the Streptoverticillium mobaraense microbe, transglutaminase was originally developed in Japan for industrial food production, and it has been in use in the United States since 1998. When applied to meat, it crosslinks the amino acids glutamine and lysine, bonding together two protein surfaces. Its primary use in the United States is to join scraps of meat into solid chunks, produc- ing uniform-sized meat portions such as chicken nuggets and imitation crab. As with other molecular gastronomy techniques, pioneering chefs have taken it out of the industrial setting and brought it to high-end restaurants with creative flair. Diners can now enjoy such off-the-wall dishes as lobster noodles (long noodles made almost entirely from lobster meat), lobster "cheetos" (puffed and fried lobster meat), and chimera fish fillets (tuna and salmon steaks fused together).

Our minibar experience included many other exciting dishes, with unusual and surprisingly delicious combinations (such as smoked eel with cotton candy, and blue cheese with almonds). As the meal drew to a close and we were savoring the last traces of the flavors, the chefs walked out behind us and placed a small eggshell in front of each diner. With one coordinated move, they smashed the shells into a thousand pieces-revealing the rolledup bills, which they had hidden inside.

FOR FURTHER READING: "The History of Molecular Gastronomy," EMBO Reports 7 (11) 1062 (2006); Foams: http:/ / www.acs. ucalgary.ca/ schramm/ (accessed July 2009); and Recipes: http:/ / khymos.org/ recipe-collection.php (accessed July 2009).

Colin McCormick is a project director with the Strategic Security and Building Technologies programs at the Federation of American Scientists.

Sharka Prokes is a senior research scientist in the Electronics Science and Technology Division at the Naval Research Laboratory. 


\section{Renewable and Alternative Energy Web Portal}




\section{Eeeco \\ Changing the Way You Use and Think about AFM}
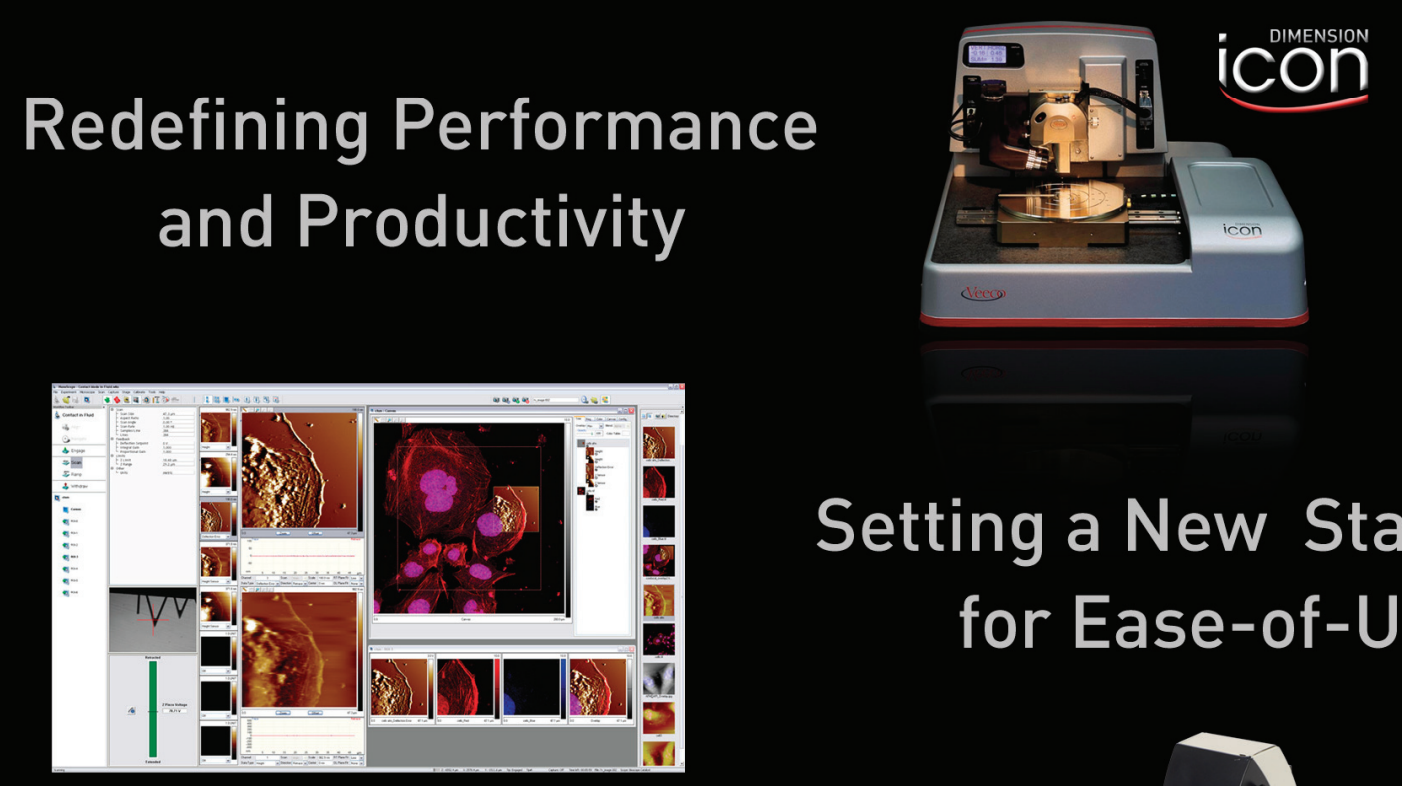

Setting a New Standard for Ease-of-Use

Delivering the World's Best AFM for Life Science
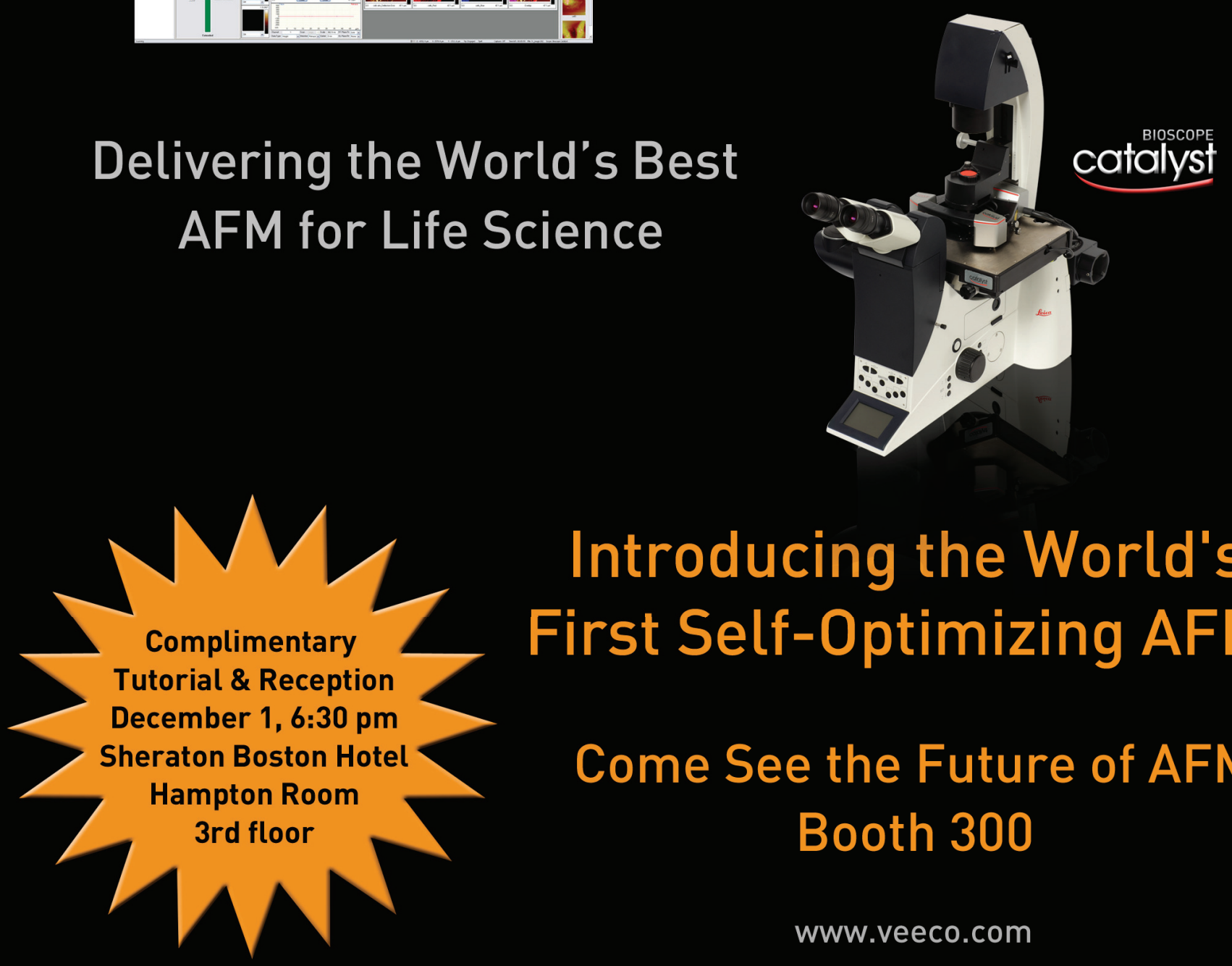

\section{Introducing the World's} First Self-Optimizing AFMs

Come See the Future of AFM Booth 300 